Original Research Paper

\title{
Novel LC-MS/MS Method for CJ-023423 (Grapiprant) Determination in Rabbit Plasma
}

\author{
${ }^{1}$ Elena Baralla, ${ }^{1}$ Virginia De Vito, \\ ${ }^{1}$ Maria Vittoria Varoni, ${ }^{2}$ Mario Giorgi and ${ }^{1}$ Maria Piera Demontis \\ ${ }^{I}$ Department of Veterinary Medicine, University of Sassari, Via Vienna, Sassari, Italy \\ ${ }^{2}$ Department of Veterinary Sciences, University of Pisa, Via Livornese (lato monte), San Piero a Grado, Pisa, Italy
}

Article history

Received: 26-02-2018

Revised: 28-02-2018

Accepted: 15-05-2018

Corresponding Author:

Mario Giorgi

Department of Veterinary

Sciences, University of Pisa,

Via Livornese (lato monte), San

Piero a Grado, Pisa, Italy

Email: mario.giorgi@unipi.it

\begin{abstract}
Grapiprant is a new anti-inflammatory drug that preferentially targets the EP4 receptor of prostaglandin E2 limiting the wide range of adverse effects caused by the classical non steroideal anti-inflammatory drugs. The aim of this study was to develop and validate a new, simple, sensitive and rapid Liquid Chromatography tandem Mass Spectrometry method (LC-MS/MS) in order to quantify this novel drug in plasma. The method involved a simple liquid extraction followed by a gradient elution with formic acid $0.2 \%$ in water and acetonitrile in reverse phase chromatography. The method was validated according to international guidelines determining selectivity, linearity, sensitivity, recovery, matrix effect and precision. Linearity was obtained over a range of 5-1000 $\mathrm{ng} \mathrm{mL}^{-1}$. The obtained Limit of Quantitation (LOQ) and of Determination (LOD) were of 5 and $1.5 \mathrm{ng} \mathrm{mL}^{-1}$ respectively. Extraction recovery was $>73 \%$ for all the tested concentrations. Matrix effect, expressed as ion suppression, was $\leq 9 \%$. The intraday and inter-day precision results showed good RSD values. All the validation parameters were satisfactory making this new method an interesting tool for scientists to further investigations on pharmacokinetics parameters. This validated method was applied to assess the pharmacokinetic of grapiprant in one rabbit administered with $0.5 \mathrm{mg} \mathrm{kg}^{-1}$.
\end{abstract}

Keywords: Grapiprant, LC-MS/MS, Plasma, Pharmacokinetics

\section{Introduction}

Grapiprant $(\mathrm{CJ}-023,423)$ is the pioneer drug of the newly recognized class of drug named priprant (WHO, 2013). Its discovery plays an important role in the treatment of osteoarthritis and inflammatory pain (Giorgi, 2014). Commonly these pathologies are handled with Nonsteroidal Anti-Inflammatory Drugs (NSAIDs) and selective Cyclooxygenase (COX)-2 inhibitors. Although these commonly used drugs are actually efficient in the reduction of pain and inflammation, their use is correlated with well-known side effects. Indeed NSAIDs act by inhibiting the two COX isoforms (COX1 and COX-2 isoforms). The COX-1 inhibition is shown to induce adverse gastrointestinal effects such as gastric erosion, ulceration and hemorrhage (Khan and McLean, 2012). The COX-2 inhibition has been recently found to correlate with kidney toxicity (Kim and Giorgi, 2013).
For these reasons the discovery of a new drug, able to block only the prostaglandin receptor without impacting the other prostanoid produced by the COX enzymes, constitutes an important breakthrough (Rausch-Derra et al., 2015). Currently, grapiprant is under development in humans and approved in dogs (USA) against the inflammation related to osteoarthritis (Giorgi, 2014). Grapiprant acts through a selective antagonism of the PGE2 receptor EP4 that has been identified as a major receptor in the mediation of pain associated with rheumatoid arthritis, osteoarthritis and inflammatory states (Chen et al., 2010; Clark et al., 2008; RauschDerra et al., 2016a). Given its novelty, very few data are reported in literature about this new drug especially regarding its pharmacokinetic profile (Rausch-Derra and Rhodes, 2014; 2016; Rausch-Derra et al., 2016b; Łebkowska-Wieruszewska et al., 2017a,b; De Vito et al., 2017). To date, only one study is available in 
literature regarding the quantification of grapiprant in canine plasma using a validated method through liquid chromatography associated with a spectrofluorometric detector (De Vito et al., 2016). Actually, LC-MS-MS techniques are largely used for the quantification of xenobiotics in biological matrices given their high sensitivity, selectivity and total analysis time reduction compared with other analytical methods. The aim of this study was to develop and validate a new LCMS/MS method able to quantify grapiprant in order to explore its pharmacokinetic profile in rabbits.

\section{Materials and Methods}

\section{Chemicals and Reagents}

Grapiprant analytical standard ( $>99.0 \%$ purity) was obtained from Cayman Chemical (Ann Arbor, MI, USA). The Internal Standard (IS) 1,1cyclohexanediacetic acid monoamide was purchased from Sigma Aldrich, (Milano, Italy). All reagents and solvents used were of the highest commercial quality and were obtained from Sigma-Aldrich (Milan, Italy). Deionized and distilled water was filtered through a Milli-Q water system (Millipore, Billerica, MA, USA). Stocks standard solutions of grapiprant $1 \mathrm{mg} \mathrm{mL}^{-1}$ were prepared in methanol and used to prepare working solutions. Calibration samples were prepared by spiking working solutions into blank rabbit plasma to yield concentrations of 5.0, 10, 50, 100, 200, 400, 800

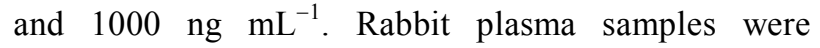
supplied by the blood bank of Veterinary Hospital at the University of Pisa.

\section{Sample Extraction}

Simple liquid-liquid extraction was developed in order to extract grapiprant from rabbit plasma. Four $\mathrm{mL}$ of acetonitrile were added to $500 \mu \mathrm{L}$ of plasma. After vortexing for $30 \mathrm{sec}$, the mixture was transferred to an ultrasonic bath for $10 \mathrm{~min}$ and then centrifuged at $20000 \mathrm{~g}$ for $10 \mathrm{~min}$ at $25^{\circ} \mathrm{C}$. The supernatant was collected into a glass vial and evaporated to dryness under nitrogen. The dry residue was reconstituted in $500 \mu \mathrm{L}$ of a mixture containing $100 \mathrm{ng} \mathrm{mL}^{-1}$ of IS in $\mathrm{H}_{2} \mathrm{O}$ and $\mathrm{CH}_{3} \mathrm{CN}$ 80:20.

\section{LC-MS/MS Analysis}

LC-MS/MS analyses were performed on a Varian 310-MS triple quadrupole mass spectrometer (Varian, Palo Alto, CA, USA). Grapiprant and 1,1cyclohexanediacetic acid monoamide were detected in positive ionization (ESI+) and in multiple reaction monitoring mode (MRM). For the optimization of detection conditions, direct infusions of standard solutions $\left(500 \mu \mathrm{g} \mathrm{mL}^{-1}\right)$ were made using a $\mathrm{T}$ connection with mobile phase at a flow of $400 \mu \mathrm{L} \min ^{-1}$. The ESI source conditions were: Capillary voltage, $50 \mathrm{~V}$; drying gas temperature, $200^{\circ} \mathrm{C}$; nebulizer gas pressure, $50 \mathrm{psi}$ (both nebulizer and drying gas were high-purity nitrogen); electron multiplier voltage, $1350 \mathrm{~V}$. For operation in MS/MS mode, the collision gas used was argon with a pressure of 2 mTorr in the collision cell. The collision energies were optimized for a maximum detection of each product ion. For grapiprant and IS, three and two transitions were used respectively; the most abundant was used for the quantitation and the others were used to confirm the analyte identity. Samples were injected into a $5 \mu \mathrm{L}$ loop. Chromatographic separation was achieved with a ProStar ${ }^{\mathrm{TM}} 300$ HPLC system (Varian, Palo Alto, CA, USA) on a LUNA $\mathrm{C}_{18}$ column $(5 \mu \mathrm{m}$, $100 \times 2.1 \mathrm{~mm}$ ID, Phenomenex, Bologna, Italy) fitted with a Phenomenex $\mathrm{C}_{18}$ security guard cartridge $(4 \times 2.0$ $\mathrm{mm}$ ID). A linear gradient, using a flow rate of $0.2 \mathrm{~mL}$ $\min ^{-1}$, with $0.2 \%$ formic acid in water (A) and $0.2 \%$ formic acid in acetonitrile (B) was performed as follows: $1 \mathrm{~min}$ at $20 \% \mathrm{~B}$; in $0.06 \mathrm{~min}$ solvent $\mathrm{B}$ was increased from 20 to $80 \%$ and remained constant at $80 \%$ B till $3.30 \mathrm{~min}$. Then in $30 \mathrm{sec}$ solvent B was decreased from 80 to $20 \%$ and it remained constant for $4 \mathrm{~min}$ to restore initial mobile phase conditions for the next injection. The total runtime was $8 \mathrm{~min}$.

\section{Method Validation}

Validation was based on the Food and Drug Administration guidelines for Bioanalytical Method Validation (US DHHS, 2013). The determined parameters were selectivity, linearity, Limit of Determination (LOD), Limit of Quantitation (LOQ), accuracy, precision, matrix effect and analyte stability. The selectivity of the method is the ability to differentiate and quantify the analyte also in presence of other components in the sample: It was determined analysing six blank plasma samples. Linearity was assessed by the construction of a calibration curve obtained fortifying blank plasma with known amounts of grapiprant ranging from $5 \mathrm{ng} \mathrm{mL} L^{-1}$ to $1 \mu \mathrm{g} \mathrm{mL}^{-1}$ and each concentration was analysed in triplicate. Calibration curve was derived from the peak area ratios (grapiprant/IS) using $1 / \mathrm{x}^{2}$ weighted linear least-squares regression of the area ratio versus the concentration of the corresponding standard.

The Limit of Detection (LOD) and the Limit of Quantitation (LOQ) were calculated using the signal-tonoise criteria of 3 and 10 , respectively.

Accuracy was determined as \% recovery. To assess this parameter, blank samples were spiked to final concentrations of 50, 400 and $800 \mathrm{ng} \mathrm{mL}^{-1}(n=5)$. Recovery was calculated by comparing the analytical results for extracted samples at the three concentrations mentioned above with unextracted standards that represent $100 \%$ of recovery. 
The precision of the method was determined using the concentrations of 50,400 and $800 \mathrm{ng} \mathrm{mL}^{-1}$ and expressed as the percent Relative Standard Deviation (RSD). The sample Standard Deviation (SD) was calculated for five replicates for each level for the intra-day precision and over five consecutive days for the inter-day precision.

Matrix effect in ion suppression or enhancement was determined using the post extraction method: Blank extracted plasma was fortified with 50, 400 and $800 \mathrm{ng}$ $\mathrm{mL}^{-1}$ of the analyte and obtained areas were compared with those obtained by the standards solutions at the same concentrations using the following equation:

$$
\text { Matrix effect }(\%)=\frac{R P-R S}{R S} \times 100
$$

where, $R P$ is the "mean peak area of reconstituted extract in plasma" and $R S$ is the "mean peak area of the reference solution".

The freeze-thaw stability of the analyte was determined in plasma at two concentrations (50 and 400 $\mathrm{ng} \mathrm{mL^{-1 }}$ ) in triplicates. Bench-top stability in plasma up to $4 \mathrm{~h}$, freeze-thaw stability from $-20^{\circ} \mathrm{C}$ to ambient temperature in plasma (up to three cycles) and the stability of the analyte in stock solution at both $4^{\circ} \mathrm{C}$ (for 37 days) and room temperature (for $17 \mathrm{~h}$ ), were evaluated.

\section{Animals}

Blood samples were obtained from one healthy male New Zealand Rabbit administered with an intravenous injection of grapiprant $\left(0.5 \mathrm{mg} \mathrm{kg}^{-1}\right)$ in the arterial of the right ear. The drug was prior dissolved in ethanol $(10 \mathrm{mg}$ $\left.\mathrm{mL}^{-1}\right)$, then diluted with sterile water for injection $(9: 1$ $\mathrm{v}: \mathrm{v})$ and immediately injected (injection rate $5 \mathrm{~mL} \mathrm{~min}^{-1}$ ). Blood (2 to $3 \mathrm{~mL}$ ) was collected via catheter, previously inserted in the left arterial of the ear, at assigned times $(0$, $15,30,45 \mathrm{~min}$ and $1,2,4,6,8,10$ and $24 \mathrm{~h})$ and immediately placed into collection tubes containing lithium heparin. The samples were centrifuged at $1,006 \mathrm{~g}$ within 30 min of collection and the harvested plasma was frozen immediately and stored at $-20^{\circ} \mathrm{C}$. Samples were analysed within 1 week from the collection. Immediately prior to the analysis, the samples were thawed at room temperature. Standard animal care and handling were performed according to the Directive 2010/63/UE.

\section{Pharmacokinetic Analysis}

The pharmacokinetic calculations were carried out using WinNonlin v 5.3.1 (Pharsight Corp, Sunnyvale, CA, USA). The area under the concentration versus time curve $\left(\mathrm{AUC}_{0}\right.$. ${ }_{\infty}$ ) was calculated using the linear trapezoidal rule. Changes in plasma concentrations of grapiprant were evaluated using the standard non compartmental analysis and the relative pharmacokinetic parameters were determined using standard non compartmental equations (Gibaldi, 1982).

\section{Results}

\section{Optimization of the Extraction Method}

Sample clean-up is a critical step especially when complex matrices such as plasma are analyzed. Two liquid-liquid extractions were compared in the first phase of this work using $\mathrm{CHCl}_{3}$ and $\mathrm{CH}_{3} \mathrm{CN}$ in order to identify the solvent that best fitted our purpose. $\mathrm{CH}_{3} \mathrm{CN}$ gave the best result with a mean recovery of $82.2 \%$ against a mean recovery of $66.4 \%$ obtained with $\mathrm{CHCl}_{3}$.

\section{LC-MS/MS Analysis and Method Validation}

Preliminary experiments were carried out by analysing six blanks plasma to evaluate the interference of the matrix (selectivity) and no interfering endogenous substances at the retention times of the analyte and IS were detected. Figure 1A shows the chromatogram of a plasma sample spiked with $50 \mathrm{ng} \mathrm{mL} L^{-1}$ of grapiprant and $100 \mathrm{ng} \mathrm{mL}^{-1}$ of IS. Quantitative analysis was carried out in ESI positive and in MRM by selecting three precursor/product ion transitions for grapiprant and two for the internal standard. The selection of the MRM transitions was made on the basis of the best signal-tonoise ratios obtained. The transitions used for the quantitation were $495.5 \mathrm{~m} / \mathrm{z} \rightarrow 295.5 \mathrm{~m} / \mathrm{z}(\mathrm{CE}=-21 \mathrm{eV})$ and $200.4 \mathrm{~m} / z \rightarrow 182.1 \mathrm{~m} / \mathrm{z}(\mathrm{CE}=-9 \mathrm{eV})$ for grapiprant and IS respectively. With the chromatographic conditions used, grapiprant and IS had a retention time of 2.6 and 2.7 minutes respectively. The linearity of the chromatographic response in the investigated range of concentrations (5-1000 $\mathrm{ng} \mathrm{mL}$ ) was evaluated with the construction of a calibration curve in rabbit plasma fortified with standard solutions of grapiprant and the correlation coefficient $(r)$ was 0.99 . The obtained LOD and LOQ were 1.5 and $5 \mathrm{ng}$ $\mathrm{mL}^{-1}$ respectively, suggesting a good sensitivity of the method. Recoveries, assessed at 50, 400 and $800 \mathrm{ng} \mathrm{mL}^{-1}$, ranged from 73.3 to $97.1 \%$; matrix effect, expressed as ion suppression, was $\leq 9 \%$. The intraday and inter-day precision results showed good RSD values, all within the acceptable limits (Table 1).

No significant loss or deterioration of the analyte was observed after $4 \mathrm{~h}$ at room temperature and after three freeze-thaw cycles from $-20^{\circ} \mathrm{C}$ to room temperature. The analyte stability was also verified up to 37 days at $4^{\circ} \mathrm{C}$ and for $17 \mathrm{~h}$ at room temperature (data not shown). Obtained results indicate the absence of stability-related problems during a pharmacokinetic analysis of grapiprant.

\section{In Vivo Application}

The proposed LC-MS-MS method was applied to a pharmacokinetic study in a rabbit after a single $0.5 \mathrm{mg} \mathrm{kg}^{-1}$ intravenous injection. Plasma was collected at established times and the developed analysis confirmed the presence of grapiprant in time related amounts (Fig. 2). The concentrations of grapiprant in plasma ranged from 
$1106.66 \mathrm{ng} \mathrm{mL}^{-1}$ (after $15 \mathrm{~min}$ from the injection) to 5.8 $\mathrm{ng} \mathrm{mL} \mathrm{L}^{-1}$ (after $6 \mathrm{~h}$ from the injection). The analyte was quantified up to $6 \mathrm{~h}$ from the injection. The described method allowed monitoring of the concentration versus time curve of the drug and the calculation of the basic pharmacokinetic parameters (Table 2). A chromatogram of the plasma sample collected after $15 \mathrm{~min}$ is reported in Fig. 1B.
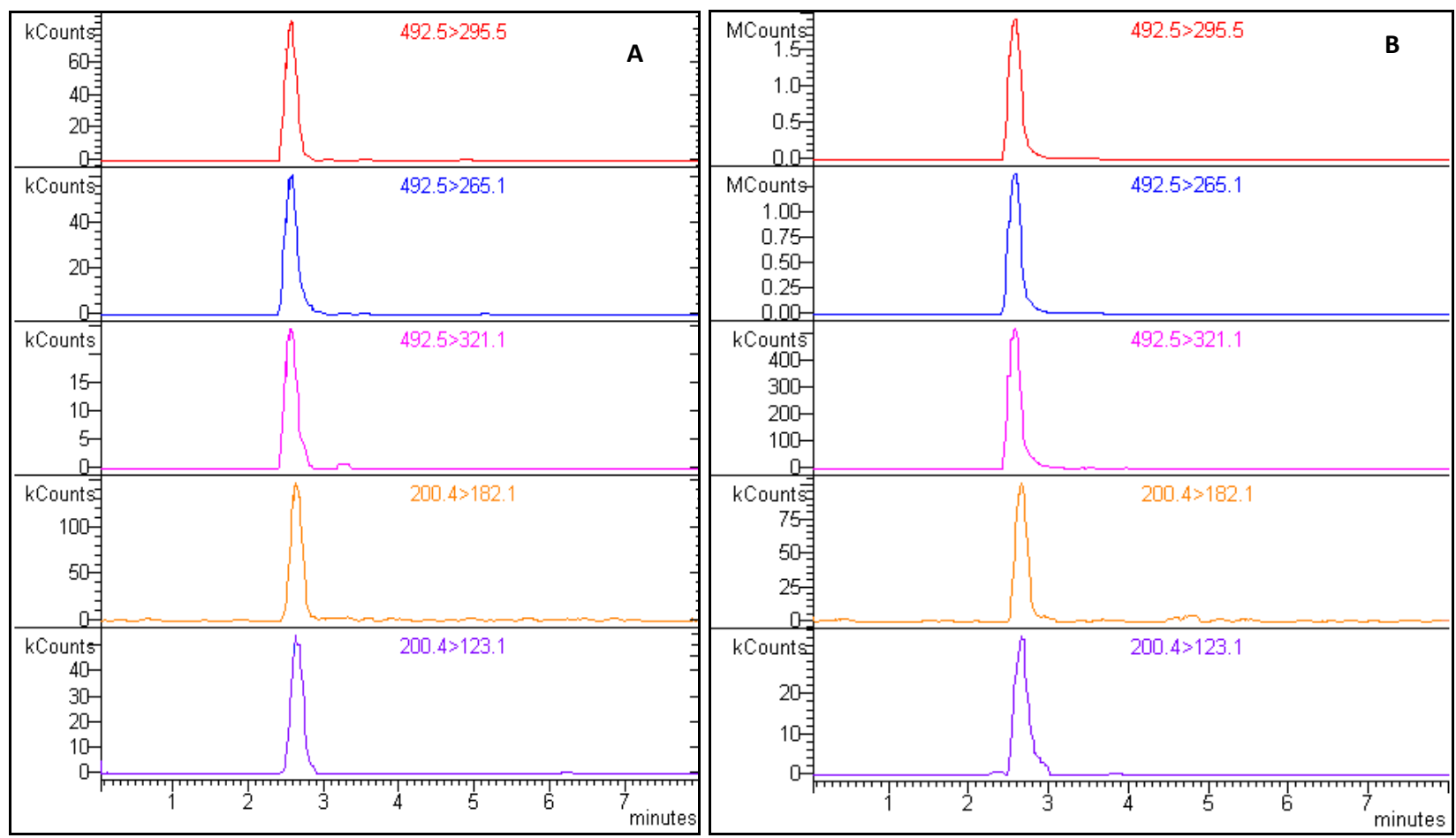

Fig. 1: Chromatogram of a rabbit plasma sample spiked with $50 \mathrm{ng} \mathrm{mL} L^{-1}$ of grapiprant and $100 \mathrm{ng} \mathrm{mL}^{-1}$ of IS (A); Chromatogram of a rabbit plasma sample collected after $15 \mathrm{~min}$ from the grapiprant $\left(0.5 \mathrm{mg} \mathrm{Kg}^{-1}\right)$ intravenous injection (B)

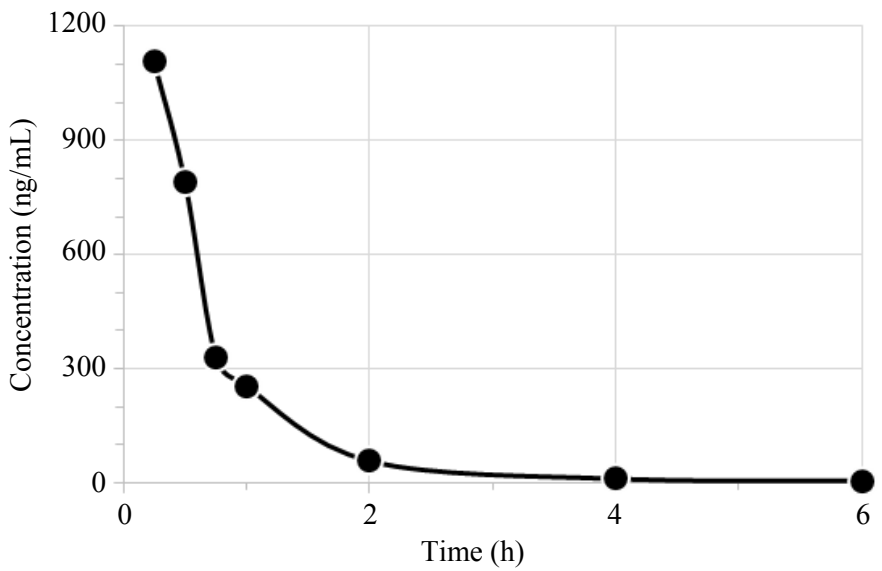

Fig. 2: Plasma concentrations of grapiprant after a single intravenous administration $(0.5 \mathrm{mg} / \mathrm{kg} \mathrm{BW})$ in one rabbit

Table 1: Recovery, matrix effect and precision

\begin{tabular}{lllllr}
\hline Matrix & $\begin{array}{l}\text { Grapiprant } \\
(\mathrm{ng} / \mathrm{mL})\end{array}$ & $\begin{array}{l}\text { Recovery }(\%) \\
(\mathrm{n}=10)\end{array}$ & $\begin{array}{l}\text { Matrix effect }(\%) \\
(\mathrm{n}=10)\end{array}$ & $\begin{array}{l}\text { Intraday RSD (\%) } \\
(\mathrm{n}=5)\end{array}$ & $\begin{array}{l}\text { Interday RSD (\%) } \\
(\mathrm{n}=5)\end{array}$ \\
\hline Plasma & 50 & 97.1 & -9.0 & 5.9 & 10.1 \\
& 400 & 76.3 & -8.7 & 3.5 & 12.1 \\
& 800 & 73.3 & -8.5 & 4.8 & 7.5 \\
\hline
\end{tabular}

RSD: Relative Standard Deviation 
Table 2: Main pharmacokinetics parameters of grapiprant following single Intravenous (IV) $0.5 \mathrm{mg} \mathrm{kg}{ }^{-1}$ administration in one healthy rabbit

\begin{tabular}{|c|c|}
\hline Parameters & Grapiprant \\
\hline $\mathrm{R}^{2}$ & 0,936 \\
\hline$\lambda z(1 / h)$ & 0,7937 \\
\hline $\mathrm{t}_{1 / 2} \lambda \mathrm{z}(\mathrm{h})$ & 0,8734 \\
\hline $\mathrm{T}_{\max }(\mathrm{h})$ & 0,25 \\
\hline $\mathrm{C}_{0}(\mu \mathrm{g} / \mathrm{mL})$ & 1545,82 \\
\hline $\mathrm{Vd}(\mathrm{mL} / \mathrm{kg})$ & 613,025 \\
\hline $\mathrm{Cl}(\mathrm{mL} / \mathrm{h} / \mathrm{kg})$ & 486,531 \\
\hline $\operatorname{AUC}_{0 \text {-last }}(\mathrm{h} \mu \mathrm{g} / \mathrm{mL})$ & 1022,95 \\
\hline $\mathrm{AUC}_{0-\infty}(\mathrm{h} \mu \mathrm{g} / \mathrm{mL})$ & 1030,26 \\
\hline $\operatorname{AUMC}_{0-\infty}\left(\mathrm{h}^{2} \mu \mathrm{g} / \mathrm{mL}\right)$ & 734,332 \\
\hline MRT (h) & 0,6963 \\
\hline Vss (mL/kg) & 338,795 \\
\hline
\end{tabular}

$\mathrm{R}^{2}=$ correlation coefficient; $\lambda \mathrm{z}=$ terminal phase rate constant; $\mathrm{t}_{1 / 2} \lambda \mathrm{z}=$ terminal half-life; $\mathrm{T}_{\max }=$ time of peak; $\mathrm{C}_{0}=$ peak plasma concentration at time zero; $\mathrm{Vd}=$ volume of distribution; $\mathrm{Cl}=$ total body clearance; $\mathrm{AUC}_{0 \text {-last }}=$ area under the plasma concentration-time curve; $\mathrm{AUC}_{0-\infty}=$ area under the plasma concentration-time curve extrapolated to infinity; $\mathrm{AUMC}_{0-\infty}=$ area under the first moment curve from zero to infinity; MRT = mean resident time; Vss $=$ Volume of distribution at the steady state

\section{Discussion}

This is the first report to describe a validated method for the quantification of grapiprant in plasma matrix through LC-MS/MS. In recent years, the LCMS/MS technique is considered the most suitable one for the quantitation of drugs in biological matrices because of its high sensitivity and selectivity. In addition, LC-MS/MS showed the advantage of unambiguous analyte identification without further time consuming and error-prone confirmation steps with excellent sensitivity and specificity. Compared with the HPLC-FL method reported in literature by De Vito et al. (2016), an improvement in the LOQ and in the total analysis time is evident. More importantly, the sensitivity of the method reported here was well below the minimum effective concentration of grapiprant reported for dogs (114-164 $\mathrm{ng} \mathrm{mL} \mathrm{mL}^{-1}$ ) (Nagahisa and Okumura, 2017) and suggested that the method would be suitable for further in vivo studies of grapiprant in plasma.

\section{Conclusion}

The analytical method described in this study provides selective and accurate analysis of grapiprant without the need for expensive clean up steps, solvent consuming flows or time consuming procedures. Moreover, only small amounts of plasma are required, which is important for pharmacokinetic studies of grapiprant in smaller animals (e.g., cats). The low LOQ shows that the method could be useful for drug measurement even when administered in sub-clinical doses. These features make the described method suitable for pharmacokinetic investigations including drug-drug interaction and potential future applications such as guidance for dose adjustment.

\section{Authors Contributions}

Elena Baralla: Carried out the experiment, contributed to sample preparation took the lead in writing the manuscript.

Virginia De Vito: Carried out the experiment, contributed to sample preparation.

Maria Vittoria Varoni: Aided in interpreting the results and worked on the manuscript.

Mario Giorgi: Conceived of the presented idea, designed and directed the project.

Maria Piera Demontis: Worked out almost all of the technical details and preformed the numerical calculations of the suggested experiment.

\section{Conflict of Interest Statement}

The authors declare that they have no conflict of interest.

\section{References}

Chen, Q., K. Muramoto, N. Masaaki, Y. Ding and H. Yang et al., 2010. A novel antagonist of the prostaglandin $\mathrm{E}(2) \mathrm{EP}(4)$ receptor inhibits Th1 differentiation and Th17 expansion and is orally active in arthritis models. Br. J. Pharmacol., 160: 292-310. DOI: 10.1111/j.1476-5381.2010.00647.x

Clark, P., S.E. Rowland, D. Denis, M.C. Mathieu and R. Stocco et al., 2008. MF498 [N-\{[4-(5,9-Diethoxy-6oxo-6,8-dihydro-7H-pyrrolo[3,4-g]quinolin-7-yl)-3methylbenzyl]sulfonyl $\}-2-(2-$

methoxyphenyl)acetamide], a selective E prostanoid receptor 4 antagonist, relieves joint inflammation and pain in rodent models of rheumatoid and osteoarthritis. J. Pharmacol. Exp. Ther., 325: 425-434. DOI: 10.1124/jpet.107.134510

De Vito, V., A. Saba, H.K. Lee, H. Owen and A. Poapolathep et al., 2016. Detection and quantification of the selective EP4 receptor antagonist CJ-023423 (grapiprant) in canine plasma by HPLC with spectrofluorimetric detection. J. Pharm. Biomed. Anal., 118: 251-258. DOI: 10.1016/j.jpba.2015.11.004

De Vito, V., M. Salvadori, A. Poapolathep, H. Owen and R. Rychshanova et al., 2017. Pharmacokinetic/pharmacodynamic evaluation of grapiprant in a carrageenan-induced inflammatory pain model in the rabbit. J. Vet. Pharmacol. Ther., 40: 468-475. DOI: $10.1111 /$ jvp. 12380 
Gibaldi, M., 1982. Pharmacokinetics. 2nd Ed.

Giorgi, M., 2014. CJ-023,423 (Grapiprant) a potential novel active compound with antihyperalgetic properties for veterinary patients. Am. J. Anim. Vet. Sci. 10: 53-56. DOI: 10.3844/ajavsp.2015.53.56

Khan, S.A. and M.K. McLean, 2012. Toxicology of frequently encountered nonsteroidal antiinflammatory drugs in dogs and cats. Vet Clin. North Am. Small Anim. Pract., 42: 289-306.

DOI: 10.1016/j.cvsm.2012.01.003

Kim, T.W. and M. Giorgi, 2013. A brief overview of the coxib drugs in the veterinary field. Am. J. Anim. Vet. Sci., 8: 89-97. DOI: 10.3844/ajavsp.2013.89.97

Łebkowska-Wieruszewska, B., V. De Vito, H. Owen, A. Poapholatep and M. Giorgi, 2017. Pharmacokinetics of grapiprant, a selective EP4 prostaglandin PGE2 receptor antagonist, after $2 \mathrm{mg} / \mathrm{kg}$ oral and i.v. administrations in cats. J. Vet. Pharmacol. Ther., 40: e11-e15. DOI: 10.1111/jvp.12414

Łebkowska-Wieruszewska, B., G. Barsotti, A. Lisowski, A. Gazzano, H. Owen and M. Giorgi, 2017. Pharmacokinetics and estimated bioavailability of grapiprant, a novel selective prostaglandin E2 receptor antagonist, after oral administration in fasted and fed dogs. N. Z. Vet. J., 65: 19-23. DOI: $10.1080 / 00480169.2016 .1241727$

Nagahisa, A. and T. Okumura, 2017. Pharmacology of grapiprant, a novel EP4 antagonist: Receptor binding, efficacy in a rodent postoperative pain model and a dose estimation for controlling pain in dogs. J. Vet. Pharmacol. Ther., 40: 285-292. DOI: $10.1111 /$ jvp. 12349

Rausch-Derra, L.C. and L. Rhodes, 2014. Safety of the EP4 receptor antagonist, grapiprant, administered daily to beagle dogs for 9 months at 1,6 and 50 $\mathrm{mg} / \mathrm{Kg}$. American College of Veterinary Internal Medicine Nashville, TN.
Rausch-Derra, L.C., M. Huebner and L. Rhodes, 2015. Evaluation of the safety of long-term, daily oral administration of grapiprant, a novel drug for treatment of osteoarthritic pain and inflammation, in healthy dogs. Am. J. Vet. Res., 76: 853-859. DOI: 10.2460/ajvr.76.10.853

Rausch-Derra, L.C and L. Rhodes, 2016. Safety and toxicokinetic profiles associated with daily oral administration of grapiprant, a selective antagonist of the prostaglandin E2 EP4 receptor, to cats. Am. J. Vet. Res., 77: 688-692.

DOI: $10.2460 /$ ajvr.77.7.688

Rausch-Derra, L., M. Huebner, J. Wofford and L. Rhodes, 2016a. A Prospective, randomized, masked, placebo-controlled multisite clinical study of grapiprant, an EP4 Prostaglandin Receptor Antagonist (PRA), in dogs with osteoarthritis. J. Vet. Intern. Med., 30: 756-763. DOI: $10.1111 /$ jvim. 13948

Rausch-Derra, L.C., L. Rhodes, L. Freshwater and R. Hawks, 2016b. Pharmacokinetic comparison of oral tablet and suspension formulations of grapiprant, a novel therapeutic for the pain and inflammation of osteoarthritis in dogs. J. Vet. Pharmacol. Ther., 39: 566-571. DOI: $10.1111 /$ jvp.12306

US DHHS, 2013. Guidance for industry Bioanalytical Method Validation. CDER and CVM. U.S. Department of Health and Human Services.

WHO, 2013. Pre-stems: Suffixes used in the selection of INN. World Health Organization. 